\title{
Model Residual Stress by Finite Element Method
}

\author{
Delia Garleanu ${ }^{1, *}$, Claudia Borda ${ }^{1}$, Gabriel Garleanu ${ }^{1}$, and Victor Popovici ${ }^{1}$ \\ ${ }^{1}$ UPB, IMST Faculty, TMS Department, 060042 Splaiul Independentei 313, Bucharest, Romania.
}

\begin{abstract}
This paper presents an original model developed by finite element method to simulate the behavior of the material to the method "Blind Hole Drilling", to determine the residual stress. Modeling of this method is possible through the use of the "Birth and Death" which have some elements of ANSYS library. After obtaining the analysis of movements, appropriate loads, a node located from the center hole at a radius calculated. In this way it is easier to estimate the stresses and deformations of a piece. Several measurements are made and based on this model is given in ANSYS. In this way we can have a map of tensions and deformations in a material
\end{abstract}

\section{Introduction}

One of the most common methods of residual stress measurement technique is the method " Blind Hole Drilling " .

Underthis method, after installingthepieceof sensors (strain gauges) is practicedshallowholeand surfacemodificationstate ofdeformationmeasuredin the vicinity ofthe hole.Fromexperimental dataobtainedcan be calculatedresidual stressesrelaxed(released).

This method is consideredsemidestructiveas long as thesmallholeinmost casesnotsignificantly affectthe structural integrityof the partbeing tested.It is atypicalhole $\mathrm{D}_{0}=1 / 16^{\prime \prime}=1,5 \mathrm{mmandD}_{0}=1 / 8 "=3,0 \mathrm{mmboth}$ indepthanddiameter.If necessary, the hole canbe coveredafter measurement. This is astandardtest method, developedby the AmericanSociety forTestingand Materials(ASTM 837). Figure 1 shows the drilling device RS-200 model.

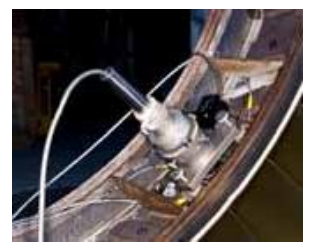

Fig. 1. End-Mill Drilling RS-200 model.

\section{Principle of the method "Blind Hole Drilling"}

Practice of hole (even very small diameter) in a body residual stress, relax tension in that place because the normal stress at any free surface (in this case the surface hole) must necessarily be zero. Elimination normal stress at the edge of the hole reduce tensions in the region surrounding vicinity, causing local deformations to be amended accordingly. Measuring strain changes caused by stress relaxation provides the necessary data for calculation. When you take avery small hole diameter (fig.2) in a region containing residual stresses, deformations sizes at point $\mathrm{P}$ are functions of the main local stress $\sigma_{\mathrm{p}}$ and $\sigma_{\mathrm{q}}$ and the geometric relationship between point and hole between point and principal axes.

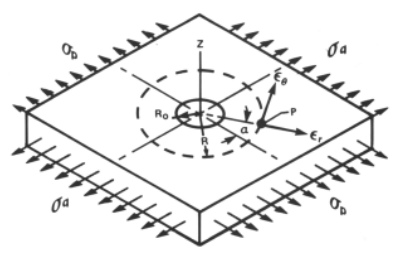

Fig. 2. Strain relaxation at point "P" due to a hole practice.

For example, if one considers deformations of the point where the main stressis present only $\sigma_{\mathrm{p}}$, then we can write the relations:

$$
\begin{aligned}
& \varepsilon_{r}=-\sigma_{p} \frac{1+v}{2 E}\left[\frac{1}{r^{2}}-\frac{3}{r^{4}} \cos 2 \alpha+\left(\frac{4}{1+v}\right) \frac{1}{r^{2}} \cos 2 \alpha\right] \\
& \varepsilon_{\theta}=-\sigma_{p} \frac{1+v}{2 E}\left[-\frac{1}{r^{2}}+\frac{3}{r^{4}} \cos 2 \alpha-\left(\frac{4 v}{1+v}\right) \frac{1}{r^{2}} \cos 2 \alpha\right]
\end{aligned}
$$

\footnotetext{
* Corresponding author: delia.garleanu@upb.ro
} 


$$
\begin{aligned}
& \gamma_{r \theta}=\frac{\sigma_{p}}{2 G}\left(\frac{3}{r^{4}}-\frac{2}{r^{2}}\right) \sin 2 \alpha \\
& \varepsilon_{r}-\varepsilon_{\theta}=-\sigma_{p} \frac{1+v}{2 E}\left(\frac{2}{r^{2}}-\frac{6}{r^{4}} \cos 2 \alpha+\frac{4}{r^{2}} \cos 2 \alpha\right)
\end{aligned}
$$

where: $\varepsilon_{\mathrm{r}}, \varepsilon_{\theta}$ are tangential or radial deformations at point $\mathrm{P} ; \gamma_{\mathrm{r} \theta}$ - shear strain at point $\mathrm{P}, \mathrm{r}=\mathrm{R} / \mathrm{R}_{0}$ dimensionless distance from the hole center point $\mathrm{P}, \mathrm{E}, \mathrm{G}, \mathrm{v}$ - module of elasticity, transverse and Poison coefficient of the material. Deformations revealed relationships expressed above are shown in figure 3 for $\alpha=0^{0}$ and $\gamma=$ $90^{\circ}$ to illustrate their variation on the main axes directions in relation to the distance (dimensionless) from the center hole.

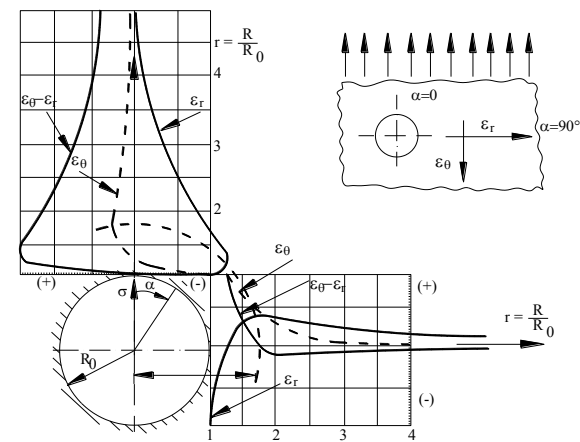

Fig. 3. Changes highlighted strains distance from the hole center (along-axis) -uniaxial residual stress.

As the distance from the hole increases, deformations decline rapidly. For this reason, to obtain a maximum signal strain gauges, it is preferable that the measurement be made as close to the hole.

On the other hand, increasing parasitic effects in the immediate vicinity of the hole. These considerations lead to the understanding of compromise in selecting the optimal range.

As shown in figure 4 is installed three rosette strain gauges oriented radially to the center of the radius $\mathrm{R}$ from the center hole. We recommend the use of specialized products rosettes "Micro-Measurements Division". Rosettes are available in two versions ( $R$ $=0.101 \mathrm{in}, \mathrm{R}=0.202 \mathrm{in}$ ) with different types of temperature compensation.
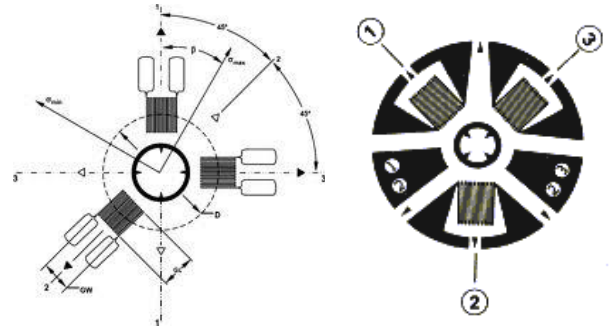

Fig. 4. Positioning rosette strain gauges for determining residual stress.

\section{Modeling by finite element method "Blind Hole Drilling"}

Finite element modeling method "Blind HoleDrilling" for determining residual stress a material can be done using the feature "Birth and Death" (activationdeactivation), which have some elements of ANSYS meshingthe library.

The "Birth and Death" every element meshis used to activate and deactivate them when material is added (or removed) from the system. Thus, some elements of the modeling "existing" or "absent". To achieve the "element death" ANSYS program does not remove disabled items but to reduce stiffness. Although the loads associated disabled elements are brought to zero, they appear in the list of elemental charges.

\subsection{Creating model}

Design geometry model begins by building a parallelepiped with dimensions of $10 \times 10 \times 4 \mathrm{~mm}$. With in this volume are defined six volumes rectangular cylinder diameter and total depth of $3 \mathrm{~mm}$ (fig. 5a).
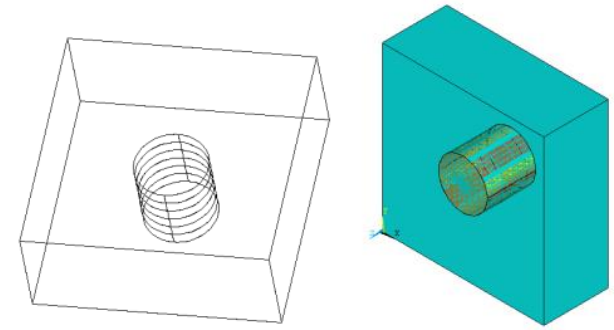

Fig.5.a Creating volumes.

Subsequently, these six volumes elements are assigned properties "Birth and Death" so that it can be modeled and incremental "Blind Hole Drilling" method. Inside this volume are defined rectangular cylindrical diameter and six volumes total depth of $3 \mathrm{~mm}$ (Fig.5 b).

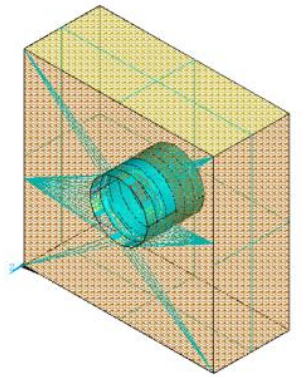

Fig.5b. Six cylindrical volume to be removed successively-incremental method

Meshing volumes (fig.6) using SOLID92 element determines obtain items totaling 16,989 nodes. 


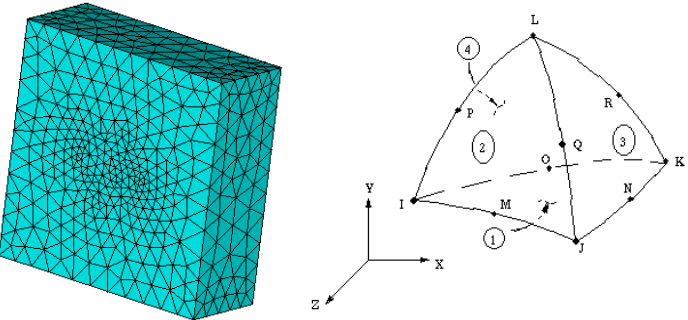

Fig. 6. Mesh elements parallelepiped volumes ( SOLID 92).

In table 1 is indicated the number of cylindrical volumes, the depth and the relevants elements.

Table 1. Hole depth and volume elements.

\begin{tabular}{|c|c|c|}
\hline No.volume & Depth $[\mathrm{mm}]$ & Elements \\
\hline 1 & 0,5 & $1-531$ \\
\hline 2 & 0,1 & $532-1107$ \\
\hline 3 & 1,5 & $1108-1676$ \\
\hline 4 & 2,0 & $1677-2245$ \\
\hline 5 & 2,5 & $2246-2815$ \\
\hline 6 & 3,0 & $2816-3389$ \\
\hline
\end{tabular}

\subsection{Application loading}

Choose the type of static analysis. For induction into the fabric of a state of biaxial tension flat areas apply lateral load displacement type (fig.7) with values between 0.01 $0.1 \mathrm{~mm}$ in six steps $(0.01,0.025,0.05,0.075,0.1 \mathrm{~mm})$.

The solution runs through seven successive runs. The first run does not disable any corresponding element cylindrical volumes. For each of the six following analysis is off by a volume cylindrical elements.
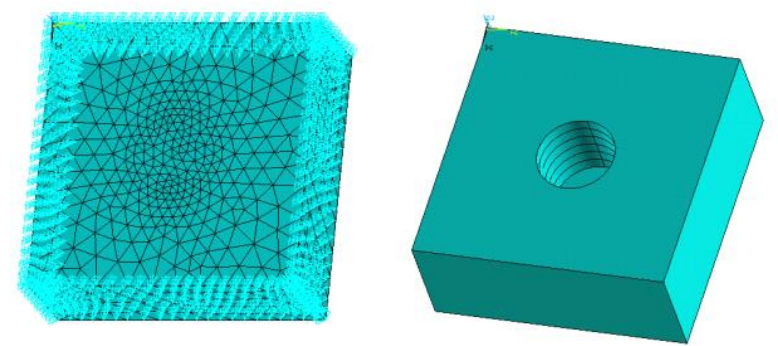

Fig.7. Application loading and off elements.

In figure 8 are represented three of the six off successive phases corresponding cylindrical hole data volumes incremental material.

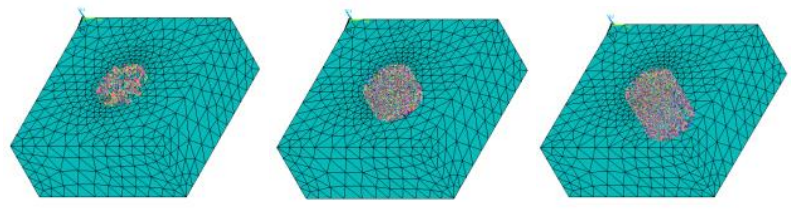

Fig. 8. Disabling successive elements of the six volumes of hole.

Finite element modeling method "Blind HoleDrilling", to determine the residual stressin a material seeking a node displacements values found on the material at a radius calculated according to the theory of strength of materials by $\mathrm{R}_{\mathrm{ph}}=2,598 \mathrm{~mm}$ from the center hole. For this purpose (fig.9), select the area on the surface of box volume (Area 41), which is measuring the deformations that occur increasing tensions by playing the hole (in a single pass at a depth equal to the diameter of the hole ori ncremental).In this area, choose a node (Node 6192) located at the radius corresponding to the calculated $(2.598 \mathrm{~mm})$. The tables with the results calculated by the processor selects the direction OX nodal displacement values corresponding to this node.

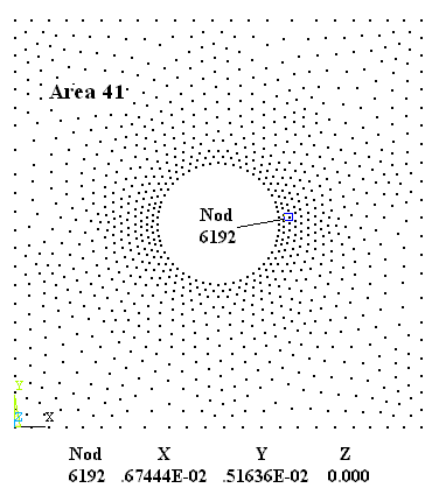

Fig.9. Selecting Node 6192 on Area 41.

The results displacements for node 6192 adequate to loads applied displacement volume of rectangular side areas that will induce tension are given in table 2.

Table 2. Nodal displacement values.

\begin{tabular}{|c|c|}
\hline $\begin{array}{c}\text { Displacement load } \\
( \pm \mathrm{UX}) /( \pm \mathrm{UY}) \\
{[\mathrm{mm}]}\end{array}$ & $\begin{array}{c}\text { Displacement UX } \\
\text { nod.6192 } \\
{[\mathrm{mm}]}\end{array}$ \\
\hline $1 \mathrm{E}-02$ & 0.0076839 \\
\hline $2.5 \mathrm{E}-02$ & 0.0019258 \\
\hline $5 \mathrm{E}-02$ & 0.0038677 \\
\hline $7.5 \mathrm{E}-02$ & 0.0058258 \\
\hline $10 \mathrm{E}-02$ & 0.0078001 \\
\hline
\end{tabular}

Graphical representation of the load-displacement pairs of values shows a very good linearity. Using a spreadsheet program is determined linear equation (fig10). 


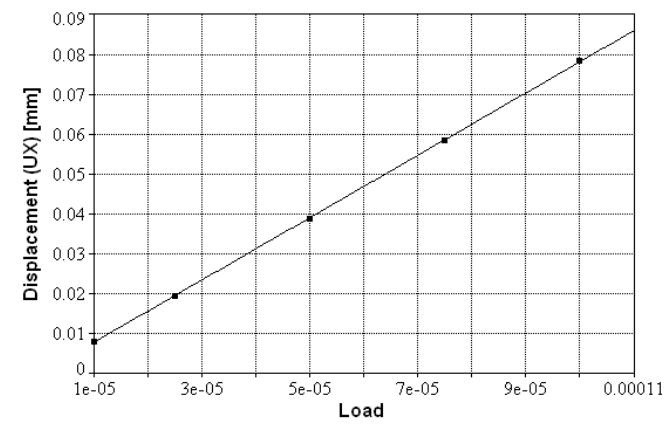

Fig. 10. Dependency relationship load - displacement.

Results strains (vonMises and Intensity) for node 6192, in order deactivation of successive volumes of the six corresponding hole until it reaches a depth value equal to its diameter are given in table 3 . Figure 11 is plotted the variation deformation (vonMises and Intensity) for node 6192 , using the data from table3.

Table 3. Values corresponding deformations volumes off

\begin{tabular}{|c|c|c|c|}
\hline $\begin{array}{c}\text { Deactivated } \\
\text { volume }\end{array}$ & Node no. & $\begin{array}{c}\text { Von Mises } \\
\text { strain }\end{array}$ & $\begin{array}{c}\text { Intensity } \\
\text { strain }\end{array}$ \\
\hline 0 & 0 & 0.009402 & 0.00942 \\
\hline 1 & $1-531$ & 0.011446 & 0.011604 \\
\hline 2 & $532-1107$ & 0.013074 & 0.013863 \\
\hline 3 & $1108-1676$ & 0.014003 & 0.015041 \\
\hline 4 & $1677-2245$ & 0.014507 & 0.015504 \\
\hline 5 & $2246-2815$ & 0.014623 & 0.015564 \\
\hline 6 & $2816-3389$ & 0.014537 & 0.015554 \\
\hline
\end{tabular}

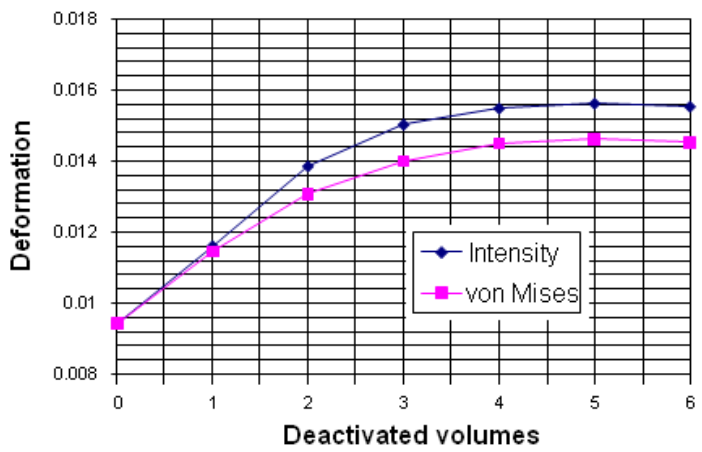

Fig. 11. Variation of deformation (von Mises and Intensity) with volume off.

In figure 12 are plotted nodal results, von Mises-section deformations resulting from successive runs that was disabled by a volume of the hole, thus simulating method "Blind Hole Drilling" incremental.
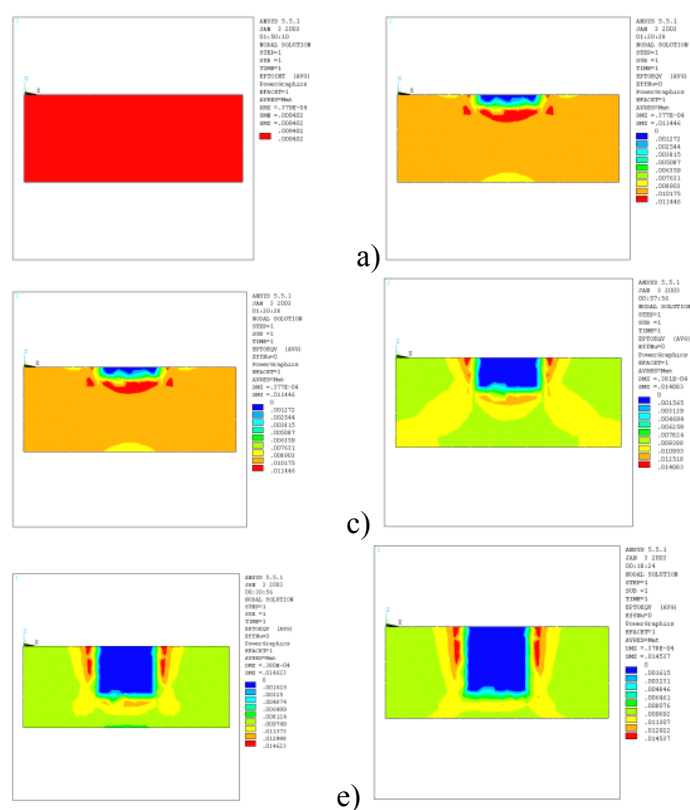

a)

b)

c)

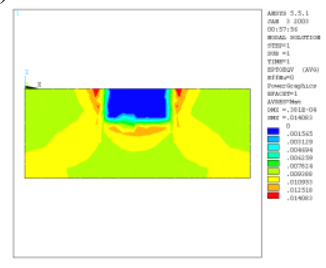

d)

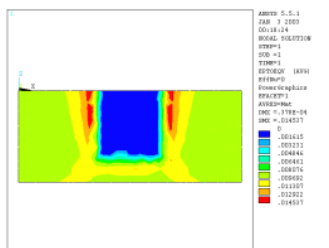

e)

f)

Fig.12. Representation of nodal results, vonMises strainsection for off successive volumes of the cylindrical hole.

To confront the results obtained from finite element modeling "Blind Hole Drilling" method with values derived from the methodology of calculation was calculated the percentage ratio of strain to the ratio depth/diameter (Z/D) equal to off successive volumes the cylindrical hole. Results are shown in table 4.

Table 3.

\begin{tabular}{|c|c|c|c|c|}
\hline \multirow{2}{*}{$\begin{array}{c}\text { Deactivated } \\
\text { volume }\end{array}$} & \multirow{2}{*}{ Z/D } & \multirow{2}{*}{\begin{tabular}{c} 
Von \\
Mises \\
\cline { 4 - 5 }
\end{tabular}} & & \multicolumn{2}{|c|}{$\begin{array}{c}\text { Percentage ratio of } \\
\text { strain } \\
\text { difference }\end{array}$} & $\%$ \\
\hline 0 & 0 & 0.009402 & 0 & 0 \\
\hline 1 & 0.166 & 0.011446 & 0.002044 & 39.149 \\
\hline 2 & 0.333 & 0.013074 & 0.003672 & 70.331 \\
\hline 3 & 0.5 & 0.014003 & 0.004601 & 88.125 \\
\hline 4 & 0.666 & 0.014507 & 0.005105 & 97.778 \\
\hline 5 & 0.833 & 0.014623 & 0.005221 & 100 \\
\hline 6 & 1.0 & 0.014537 & 0.005135 & 98.353 \\
\hline
\end{tabular}

Graphical representation of the values in Table 5 is given in Figure 13. 


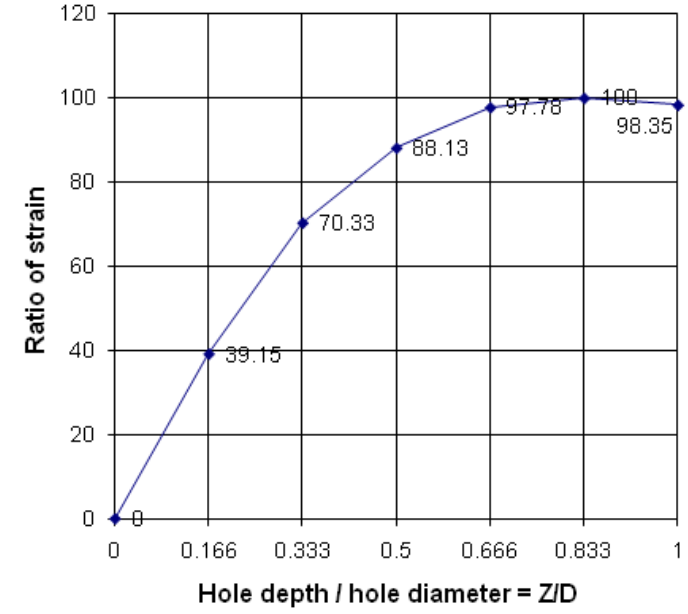

Fig.13. Ratio of strain to the ratio Z/D (depth/diameter)

\section{Conclusion}

Presented an original model developed by finite element method that simulates the behavior of the material to the method "Blind HoleDrilling", to determine the residual stress. Modeling of this method is possible through the use of the "Birth and Death" (activation-deactivation), which have some elements of ANSYS meshing library. To get the effect "element death", elements are cutoff rigidity. After the analysis results are obtained displacements corresponding loads, a node located from the center hole at a radius calculated. To confront the results of modeling by Finite Elements Method, method "Blind Hole Drilling" with values from the calculation methodologyis calculated "the percentage strain ratio" the ratio depth / diameter, resulting in deactivation of successive volumes of the cylindrical hole. In industry, the percentage of use of welded constructions / welded parts is very high. After each welding cord we have strains and deformations. Deformations are easy to see because they are visible and measurable. The state of stress in the material is determined more difficult and depending on the importance of the part, the thermal stress relief treatment is done or not. Thermal treatment involves some costs. It is necessary to know what is the level of tension in the material in the whole piece to make the decision to achieve or not the heat treatment of the piece. It is difficult to make hundreds of measurements on the same piece and therefore a finite element program can be used to simulate the residual stresses in the piece.

\section{References}

1. Measurement of Residual Stresses by the HoleDrilling Strain Gage Method.-Tech Note TN 503-6, Vishay Micro-Measurements

2. Standard Test Method for Determining Residual Stresses by the Hole-DrillingStrain-Gage Method." ASTM Standard E 837-01 2001
3. G. Gârleanu, Computerization and optimization of technological processes, Bucuresti, 2007.

4. D. Gârleanu, "Pressure Welding Technology," Ed.Bren, Bucuresti 2014

5. W.H. Lee, Computer Simulation of Shaped Charge Problem Ed. World Scientific Publishing Co. Pte. Ltd.,2006.

6. P., Krusl, A Pragmatic Introduction to the Finite Element Method for Thermal and Stress Analysis, Ed. World Scientific Publishing Co. Pte. Ltd., 2006

7. ANSYS Tutorials

8. Witt, F., F. Lee and W. Rider " $A$ Comparison of Residual Stress Measurements Using Blind-hole Drill, Abrasive Jet, Trepan Ring." Presented at Society for Experimental Stress Analysis Meeting, Dearborn, Michigan, 1981

9. Measurement Group, Inc."Measurement of Residual Stress By The Blind Hole Drilling Method" 2001

10. Rendler, N.J. and I.Vigness. "Hole-drilling Straingage Method of Measuring Residual Stresses". Proceedings of the Society of Experimental Stress Analysis. Vol. XXIII, No.2, 1996, pp. 577-586 